\title{
Crystal Chemical Design of Functional Fluoride Borates with 'Antizeolite'
}

\section{Structure}

${ }^{* 1,2,3}$ Tatyana Bekker, ${ }^{1}$ Vladimir Solntsev, ${ }^{1,2}$ Alexander Yelisseyev, ${ }^{1}$ Alexey Davydov, ${ }^{1,2}$ Sergey

Rashchenko

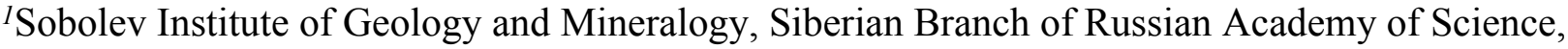
630090 Novosibirsk, Russia

${ }^{2}$ Novosibirsk State University, 630090 Novosibirsk, Russia

${ }^{3}$ Novosibirsk State University of Architecture, Design and Arts (NSUADA), 630099

Novosibirsk, Russia

*Corresponding author: bekker@igm.nsc.ru, t.b.bekker@gmail.com,

\section{Supporting Information}

SI Table S1: Fractional atomic coordinates and isotropic or equivalent isotropic displacement parameters $\left(\AA^{2}\right)$

\begin{tabular}{|c|c|c|c|c|c|c|}
\hline & $x$ & $y$ & $z$ & $U_{\text {iso }} * / U_{\text {eq }}$ & $\begin{array}{l}\text { Occ. } \\
(<1)\end{array}$ & Wyckoff \\
\hline $\mathrm{Ba} 1$ & $0.68024(5)$ & $0.33125(6)$ & 0.5 & $0.0089(2)$ & & $8 \mathrm{~h}$ \\
\hline $\mathrm{Ba} 2$ & $0.43601(4)$ & $0.20141(4)$ & $0.36736(4)$ & $0.0101(2)$ & & $16 \mathrm{i}$ \\
\hline $\mathrm{Ba} 3$ & $0.79664(4)$ & $0.57703(4)$ & 0.63438 & $0.0113(2)$ & & $16 \mathrm{i}$ \\
\hline $\mathrm{Ba} 4$ & 0.5 & 0.5 & 0.36658 & $0.0148(3)$ & & $8 \mathrm{e}$ \\
\hline F1 & $0.5745(5)$ & $0.1388(6)$ & 0.5 & $0.016(2)$ & & $8 \mathrm{~h}$ \\
\hline $\mathrm{F} 2$ & $0.8698(6)$ & $0.4326(5)$ & 0.5 & $0.021(3)$ & & $8 \mathrm{~h}$ \\
\hline $\mathrm{O} 1$ & $0.4805(6)$ & $0.3541(6)$ & 0.5 & $0.011(3)$ & & $8 \mathrm{~h}$ \\
\hline $\mathrm{O} 2$ & $0.8129(7)$ & $0.1974(7)$ & 0.5 & $0.014(2)^{*}$ & & $8 \mathrm{~h}$ \\
\hline $\mathrm{O} 3$ & $0.6466(6)$ & $0.5239(6)$ & 0.5 & $0.0114(19)^{*}$ & & $8 \mathrm{~h}$ \\
\hline $\mathrm{O} 4$ & $0.6238(5)$ & 0.2673 & $0.3306(5)$ & $0.021(2)$ & & $16 \mathrm{i}$ \\
\hline $\mathrm{O} 5$ & $0.7523(5)$ & $0.3887(5)$ & $0.6795(5)$ & $0.020(2)$ & & $16 \mathrm{i}$ \\
\hline
\end{tabular}




\begin{tabular}{|l|l|l|l|l|l|l|}
\hline O6 & $0.6186(5)$ & $0.6263(5)$ & $0.2911(5)$ & $0.015(2)$ & & $16 \mathrm{i}$ \\
\hline B1 & $0.6190(11)$ & $0.6248(11)$ & 0.5 & $0.008(3)^{*}$ & & $8 \mathrm{~h}$ \\
\hline O7 & $0.5459(9)$ & $0.0742(9)$ & $0.2760(9)$ & $0.017(3)^{*}$ & 0.5 & $16 \mathrm{i}$ \\
\hline B2 & $0.6536(8)$ & $0.6666(8)$ & $0.2130(7)$ & $0.012(3)$ & & $16 \mathrm{i}$ \\
\hline B3 & 0.5 & 0 & $0.2307(17)$ & $0.004(6)^{*}$ & 0.5 & $8 \mathrm{f}$ \\
\hline O8 & 0.5 & 0 & $0.1384(13)$ & $0.019(6)$ & 0.5 & $8 \mathrm{f}$ \\
\hline Li1 & 1 & 0.5 & $0.484(3)$ & $0.016(12)^{*}$ & 0.5 & $8 \mathrm{f}$ \\
\hline
\end{tabular}

SI Table S2: Atomic displacement parameters $\left(\AA^{2}\right)$

\begin{tabular}{|l|l|l|l|l|l|l|}
\hline & $U^{11}$ & $U^{22}$ & $U^{33}$ & $U^{12}$ & $U^{13}$ & $U^{23}$ \\
\hline Ba1 & $0.0081(4)$ & $0.0077(4)$ & $0.0108(4)$ & $0.0022(3)$ & 0 & 0 \\
\hline Ba2 & $0.0107(4)$ & $0.0104(4)$ & $0.0091(4)$ & $0.0004(2)$ & $-0.0002(2$ & $-0.0011(2)$ \\
\hline Ba3 & $0.0107(4)$ & $0.0105(3)$ & $0.0127(4)$ & $-0.0016(2)$ & $-0.0006(2$ & $0.0006(2)$ \\
\hline Ba4 & $0.0159(5)$ & $0.0188(5)$ & $0.0098(5)$ & $-0.0062(4)$ & 0 & 0 \\
\hline F1 & $0.014(4)$ & $0.014(4)$ & $0.020(5)$ & $0.001(3)$ & 0 & 0 \\
\hline F2 & $0.011(4)$ & $0.011(4)$ & $0.039(6)$ & $0.001(3)$ & 0 & 0 \\
\hline O1 & $0.008(4)$ & $0.006(4)$ & $0.019(5)$ & $-0.001(3)$ & 0 & 0 \\
\hline O4 & $0.023(4)$ & $0.026(4)$ & $0.015(4)$ & $-0.005(3)$ & $-0.002(3)$ & $0.001(3)$ \\
\hline O5 & $0.018(4)$ & $0.016(4)$ & $0.026(4)$ & $0.000(3)$ & $0.012(3)$ & $0.001(3)$ \\
\hline O6 & $0.017(4)$ & $0.014(3)$ & $0.015(4)$ & $0.006(3)$ & $0.001(3)$ & $0.001(3)$ \\
\hline B2 & $0.011(5)$ & $0.017(6)$ & $0.006(5)$ & $-0.010(5)$ & $0.004(4)$ & $-0.006(4)$ \\
\hline O8 & $0.036(12)$ & $0.013(10)$ & $0.007(11)$ & $-0.003(8)$ & 0 & 0 \\
\hline
\end{tabular}

